\title{
ANALISA PERENCANAAN PERBAIKAN KUALITAS UNTUK MENGURANGI CACAT PRODUK COFFEE CHOCOLATE CREAMER MENGGUNAKAN METODE KAIZEN (STUDY KASUS CV. GRAHA REJEKI INDONESIA)
}

\author{
Anik Rufaidah ${ }^{1)}$, Nailul Izzah ${ }^{2}$, Muhamad Rusli Efendi ${ }^{3)}$ \\ 1,2,3) Jurusan Teknik Industri, Universitas Qomaruddin Gresik \\ Email: anikrufaidah99@gmail.com
}

\begin{abstract}
ABSTRAK
Kualitas merupakan salah satu faktor terpenting dalam suatu produk untuk dapat bersaing dan menarik perhatian konsumen di pasaran. CV. Graha Rejeki Indonesia adalah perusahaan yang bergerak dalam industri manufaktur yang memproduksi olahan biji kopi menjadi kopi bubuk dengan aneka rasa. Permasalahan yang sering terjadi dilantai produksi terutama bagian proses yaitu banyaknya temuan produk cacat atau tidak sesuai dengan standart. Dari kondisi tersebut maka perlu melakukan penyelesaian terhadap penyebab kecacatan produk dengan menggunakan metode Kaizen dengan siklus PDCA dan gerakan 5S. Dari hasil analisis menunjukkan pada tabel check sheet terdapat tiga jenis kriteria cacat. Dari histogram diketahui kriteria cacat yang paling banyak adalah bubuk kopi menggumpal yakni sebesar 516 kg. Dari peta kendali P diketahui hasil nilai UCL 0,4595 dan LCL 0,1592. Nilai tersebut menunjukkan masih dalam batas kendali perusahaan. Dari diagram pareto diperoleh jenis cacat yang paling dominan adalah cacat bubuk kopi menggumpal dengan 45,1\%. Dari hasil analisis fishbone diagram diketahui penyebab kecacatan bubuk kopi menggumpal adalah faktor manusia, bahan baku, metode dan lingkungan. Setelah diketahui penyebab kecacatan, maka dilakukan perbaikan menggunakan siklus PDCA dan 5S yaitu dengan melakukan tindakan memberikan pengarahan dan bimbingan konseling pada karyawan yang melanggar, saling koordinasi dengan atasan serta selalu memelihara dan merawat tempat kerja agar dapat bekerja dengan nyaman.
\end{abstract}

Kata kunci: Kaizen, Seven tools, Siklus PDCA, Gerakan 5S.

\section{Pendahuluan}

Kualitas menempati peran yang penting dalam suatu industri karena pada dasarnya kualitas adalah suatu kreasi dan inovasi berkelanjutan yang dilakukan untuk menyediakan produk atau jasa yang memenuhi atau melampaui harapan para pelanggan dalam usaha untuk terus memuaskan kebutuhan dan keinginan konsumen. Kualitas barang yang baik dan sesuai standar akan tercapai apabila pengendalian kualitas tersebut juga baik [1], [2]. Metode Kaizen merupakan salah satu metode yang dapat menyelesaikan masalah kecacatan suatu kualitas, karena pada dasarnya konsep kaizen ini dikembangkan oleh adanya kesadaran akan timbulnya masalah [3], [4], [5]. Konsep kaizen menghasilkan pemikiran yang berorientasi pada proses karena proses harus terus diperbaiki. Selain itu, Kaizen juga berorientasi pada manusia yang ditujukan pada usaha manusia untuk memperbaiki proses produksi dengan tiga aturan dasar kaizen yaitu penghapusan pemborosan (muda), penataan (5S) dan standarisasi [6], [7].

CV. Graha Rejeki Indonesia Lamongan merupakan sebuah perusahaan yang bergerak dalam bidang produksi pengolahan biji kopi menjadi kopi bubuk yang bertempat di desa jati sari kecamatan Glagah Kabupaten Lamongan. Kopi yang diproduksi di CV. Graha Rejeki Indonesia Lamongan tersebut diantaranya adalah coffee chocolate creamer, green coffee, dan kopi giras. CV. Graha Rejeki Indonesia Lamongan juga memproduksi produk lain yakni minuman herbal. Hasil produksi dari olahan kopi tersebut di kirim ke berbagai kota di Jawa Timur khususnya kota Lamongan, Gresik, Surabaya, Jombang dan kota-kota lain di Indonesia. Ada juga yang di export ke luar negri tergantung sesuai dengan pesanan. Pada sistem produksinya CV. Graha Rejeki Indonesia Lamongan merupakan perusahaan yang menganut sistem make to order dimana perusahaan akan melakukan produksi sesuai dengan order yang diterima dan selesai pada waktu yang telah disepakati.

Proses produksi kopi di CV. Graha Rejeki Indonesia Lamongan ini terkadang apa yang diharapkan tidak sesuai dengan kenyataan, seperti halnya pada kualitas produk. Meskipun sudah melakukan pengendalian kualitas, 


\section{KAIZEN : MANAGEMENT SYSTEMS \& INDUSTRIAL ENGINEERING JOURNAL VOL. 3 NO. 2 TEKNIK INDUSTRI UNIVERSITAS PGRI MADIUN}

akan tetapi masih ditemukan produk cacat atau tidak sesuai dengan standar [3], [8], [9]. Adapun produk cacat yang didapat saat proses produksi tersebut meliputi Bubuk Kopi Menggumpal (BKM), Biji Kopi Gosong (BKG) dan Bubuk Kopi Kasar (BKK). Pada penelitian ini permasalahan tujuan yang ingin dicapai adalah untuk mengetahui faktor-faktor yang menyebabkan kerusakan atau cacat pada produk selama proses produksi pada produk coffee chocolate creamer di CV. Graha Rejeki Indonesia [10], [11]. Cara mengetahui upaya peningkatan kualitas dengan menerapkan konsep kaizen dan gerakan $5 S$.

\section{Metode Penelitian}

Dalam melakukan pengolahan data yang diperoleh, maka digunakan alat bantu pengendalian kualitas yang ada pada metode Seventools. Adapun langkah-langkahnya adalah sebagai berikut:

1. Mengumpulkan data menggunakan check sheet.

2. Membuat histogram.

3. Menentukan prioritas perbaikan (menggunakan diagram pareto) dengan persamaan 1.

Perhitungan \% Cacat $=\frac{\text { Jenis Cacat }}{\text { Jumlah Cacat }} \times 100 \%$

4. Membuat peta kendali p.

Berikut ini adalah rumus dari diagram Peta kendali P:

1) Menghitung Prosentase kerusakan mengunakan Persamaan 2

$\mathrm{P}=\frac{\mathrm{np}}{\mathrm{n}}$

Keterangan :

np $\quad$ : jumlah gagal dalam sub group

n : jumlah yang diperikasa dalam sub group

Subgroup : Hari ke-

2) Menghitung garis pusat / Central Line (CL) dengan Persamaan 3. Garis pusat merupakan rata-rata kerusakan produk $(\bar{p})$

$\mathrm{CL}=\overline{\mathrm{P}}=\frac{\Sigma \mathrm{np}}{\Sigma \mathrm{n}}$

Keterangan :

$\sum n p:$ Jumlah total yang rusak

$\sum n$ : Jumlah total yang diterima

3) Rumus untuk mencari nilai UCL pada Persamaan 4

$\mathrm{UCL}=\overline{\mathrm{p}}+3 \sqrt{\frac{\mathrm{F}(1-\overline{\mathrm{p}})}{\mathrm{n}}}$

Keterangan :

$\mathrm{p} \quad$ : rata-rata ketidak sesuaian produk

n : jumlah produksi

4) Rumus untuk mencari nilai LCL pada Persamaan 5

$\mathrm{LCL}=\overline{\mathrm{p}}-3 \sqrt{\frac{5(1-\overline{\mathrm{p}})}{\mathrm{n}}}$

5. Mencari faktor penyebab yang dominan dengan diagram sebab akibat (fishbone diagram).

6. $\quad$ Membuat usulan konsep kaizen dengan Siklus PDCA dan gerakan-gerakan 5S

\section{Hasil dan Pembahasan}

Berdasarkan hasil pengumpulan data pada penelitian yang dilakukan di CV. Graha Rejeki Indonesia Lamongan, diperoleh data hasil produksi dan data cacat untuk produk kopi coklat yang dihasilkan oleh check sheet atau lembar pengamatan yang dapat dilihat pada Tabel 1. Hasi dari Tabel 1 diketahui bahwa dari bulan Januari sampai Desember 2018 diketahui nilai kecacatan tertinggi berada pada bulan Februari dengan total kecacatan sebesar 134 dengan prosentase kecacatan sebesar 26,8\%. Hal ini dipengaruhi dengan adanya musim penghujan di bulan februari, sehingga proses pengeringan kurang maksimal. 
KAIZEN : MANAGEMENT SYSTEMS \& INDUSTRIAL ENGINEERING JOURNAL VOL. 3 NO. 2 TEKNIK INDUSTRI UNIVERSITAS PGRI MADIUN

Tabel 1. Check Sheet Kerusakan Kopi Coklat

\begin{tabular}{|c|c|c|c|c|c|c|c|}
\hline \multirow[b]{2}{*}{ No } & \multirow[b]{2}{*}{ Bulan } & \multirow[b]{2}{*}{$\begin{array}{l}\text { Jumlah } \\
\text { Produksi } \\
\text { (Kg) }\end{array}$} & \multicolumn{3}{|c|}{ Jenis Kerusakan } & \multirow{2}{*}{$\begin{array}{c}\text { Total } \\
\text { Produk } \\
\text { Cacat } \\
(\mathbf{K g})\end{array}$} & \multirow[b]{2}{*}{$\begin{array}{c}\text { Presentase } \\
\text { Kecacatan } \\
\quad(\%)\end{array}$} \\
\hline & & & $\begin{array}{c}\text { Bubuk Kopi } \\
\text { Menggumpal } \\
\text { (Kg) }\end{array}$ & $\begin{array}{c}\text { Biji Kopi } \\
\text { Gosong } \\
\text { (Kg) }\end{array}$ & $\begin{array}{c}\text { Bubuk } \\
\text { Kopi Kasar } \\
(\mathrm{Kg})\end{array}$ & & \\
\hline 1 & Januari & 700 & 68 & 17 & 29 & 114 & $16,3 \%$ \\
\hline 2 & Februari & 500 & 84 & 24 & 26 & 134 & $26,8 \%$ \\
\hline 3 & Maret & 650 & 41 & 15 & 36 & 92 & $14,2 \%$ \\
\hline 4 & April & 650 & 32 & 18 & 27 & 77 & $11,8 \%$ \\
\hline 5 & Mei & 600 & 45 & 20 & 18 & 83 & $13,8 \%$ \\
\hline 6 & Juni & 670 & 35 & 31 & 35 & 101 & $15,1 \%$ \\
\hline 7 & Juli & 650 & 27 & 25 & 40 & 92 & $14,2 \%$ \\
\hline 8 & Agustus & 600 & 54 & 22 & 22 & 98 & $16,3 \%$ \\
\hline 9 & September & 700 & 30 & 34 & 14 & 78 & $11,1 \%$ \\
\hline 10 & Oktober & 650 & 27 & 28 & 34 & 89 & $13,7 \%$ \\
\hline 11 & November & 650 & 33 & 32 & 20 & 85 & $13,1 \%$ \\
\hline 12 & Desember & 600 & 40 & 39 & 22 & 101 & $16,8 \%$ \\
\hline \multirow{2}{*}{\multicolumn{3}{|c|}{\begin{tabular}{l|l} 
Total & \\
Rata-Rata/Unit
\end{tabular}}} & 516 & 305 & 323 & 1144 & $183,2 \%$ \\
\hline & & & 43,0 & 25,4 & 26,9 & & $15,3 \%$ \\
\hline
\end{tabular}

Histogram salah satu alat didalam metode perbaikan kualitas yang berfungsi untuk memetakan distribusi atas sejumlah data [11]. Data tersebut diperoleh dari tabel check sheet yang terdapat tiga jenis kriteria kecacatan yang akan didistribusikan datanya. Untuk lebih jelasnya hasil dari distribusi 3 jenis kriteria kecacatan tersebut bisa dilihat pada Gambar 1. Hasil histogram dari Gambar 1 dapat dilihat distribusi jenis cacat yang sering terjadi adalah bubuk kopi menggumpal dengan jumlah cacat sebanyak $516 \mathrm{~kg}$. Diikuti jenis cacat bubuk kopi kasar sebanyak $323 \mathrm{~kg}$. Selanjutnya adalah jenis cacat biji kopi gosong berjumlah $305 \mathrm{~kg}$.

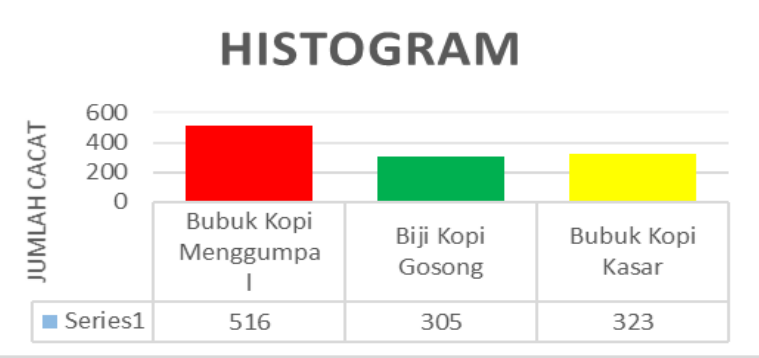

Gambar 1. Histogram Jenis Kecacatan Kopi Cokelat

Setelah membuat diagram histogram, langkah selanjutnya yaitu membuat peta kendali $\mathrm{P}$ (P Chart) yang berfungsi untuk melihat apakah pengendalian kualitas yang dilakukan perusahaan sudah terkendali atau belum [11]. Dari hasil perhitungan dapat dibuat peta kendali P yang dapat dilihat pada Gambar 2. Berdasarkan gambar grafik peta kendali P diatas dapat dilihat bahwa proporsi reject produk kopi cokelat menunjukan bahwa pada bulan Februari mempunyai proporsi cacat tertinggi yaitu sebesar 0,2680. Anak tetapi, tidak berada di luar batas kontrol atas (upper control limit). Dengan ini maka, tidak ada hal yang perlu diperbaiki karena tidak ada yang keluar dari batas kendali.

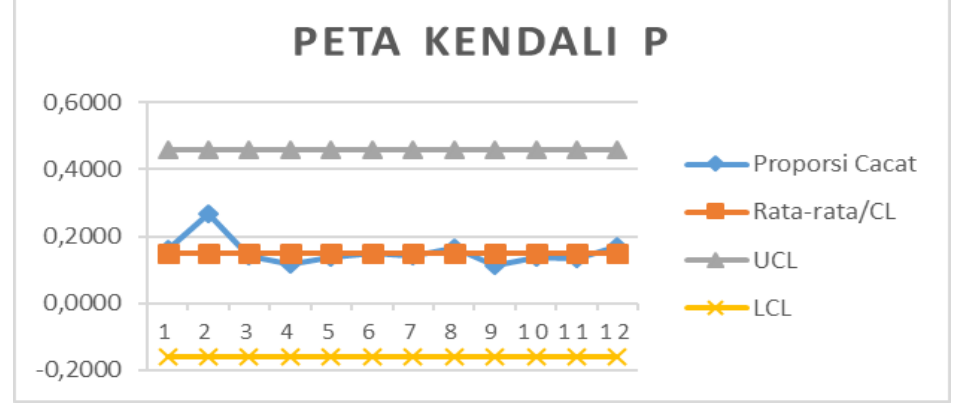

Gambar 2. Peta kendali P Cacat Kopi Coklat

Copyright (C) 2018, Kaizen : Management Systems \& Industrial Engineering Journal ISSN 15222-96806 (print), ISSN 155222-95973 (online) 


\section{KAIZEN : MANAGEMENT SYSTEMS \& INDUSTRIAL ENGINEERING JOURNAL VOL. 3 NO. 2 TEKNIK INDUSTRI UNIVERSITAS PGRI MADIUN}

Diagram pareto adalah diagram yang digunakan untuk mengidentifikasi, mengurutkan dan bekerja untuk menyisihkan kerusakan produk (misdruk) secara permanen [12]. Dengan diagram ini, maka dapat diketahui jenis misdruk yang paling dominan pada hasil produksi kopi cokelat selama dari bulan Januari sampai Desember 2018. Pada tabel 1. check sheet dapat dilihat jenis-jenis misdruk yang sering terjadi pada produk kopi cokelat. Berikut ini merupakan tabel dari jumlah misdruk/kecacatan selama periode bulan Januari sampai Desember 2018. Hasil Gambar 3 diketahui bahwa jenis kerusakan yang paling dominan adalah cacat bubuk kopi menggumpal sebanyak $516 \mathrm{~kg}$ dengan prosentase $45,1 \%$, diikuti oleh cacat bubuk kopi kasar sebanyak $323 \mathrm{~kg}$ dengan prosentase $28,2 \%$, dan cacat biji kopi gosong $305 \mathrm{~kg}$ dengan prosentase $26,7 \%$. Data tersebut berarti menunjukan cacat bubuk kopi menggumpal menjadi perhatian utama dalam perbaikan yang akan dilakukan di CV. Graha Rejeki Indonesia Lamongan untuk menekan cacat pada bubuk kopi menggumpal agar bisa lebih minim. Akan tetapi jenis reject yang lain juga harus ditekan supaya mendatangkan profit yang maksimal bagi CV. Graha Rejeki Indonesia Lamongan kedepanya.

\section{Diagram Pareto}

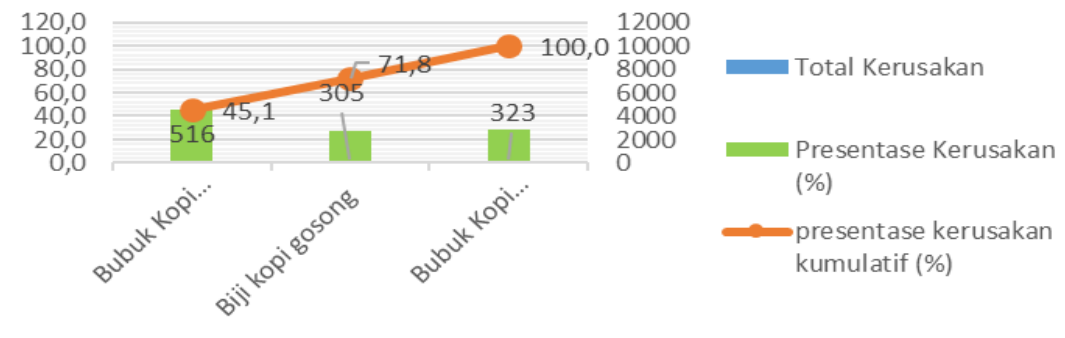

Gambar 3. Diagram Pareto Kecacatan Kopi Cokelat

Diagram Fishbone digunakan untuk mengetahui faktor-faktor yang menyebabkan kerusakan produk serta sebagai rencana pengendalian reject produk dan sebagai bahan pertimbangan dalam pengambilan keputusan untuk mengurangi jumlah reject yang terjadi [12]. Diagram fishbone disajikan pada macam kriteria cacat pada Gambar 4.

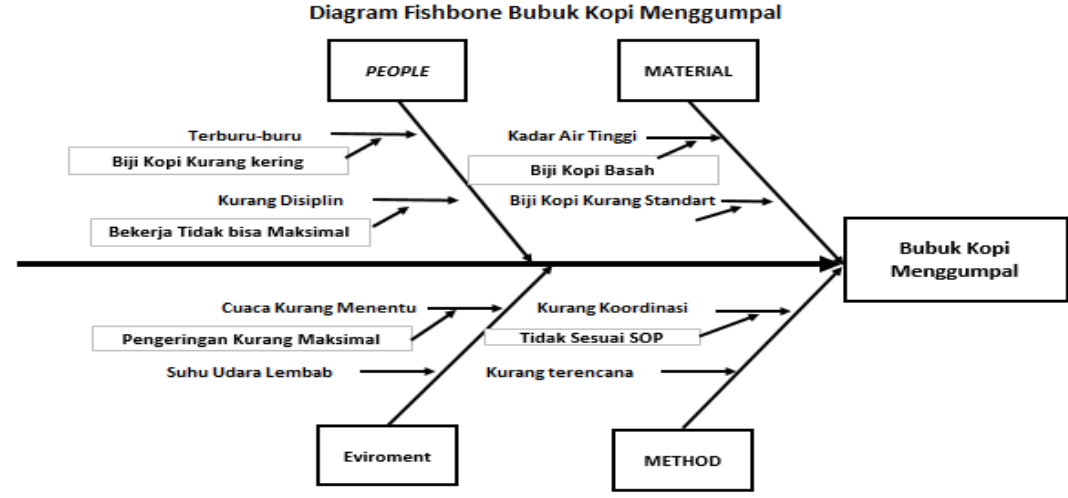

Gambar 4. Fishbone Diagram Cacat Bubuk Kopi Menggumpal

Setelah diketahui penyebab kerusakan (cacat) pada produk kopi cokelat yang terjadi di CV Graha Rejeki Indonesia, maka disusun suatu rekomendasi atau usulan tindakan perbaikan dalam upaya menekan tingkat kerusakan produk sebagai berikut:

1. Operator yang bekerja diberikan pelatihan, dan pengawasan ketika bekerja, agar ia menjadi lebih serius, hatihati dan konsentrasi dalam bekerja.

2. Setiap menerima kiriman bahan baku dilakukan pemeriksaan untuk memastikan bahwa kualitas bahan baku baik dan standar.

3. Perawatan mesin harus benar-benar dijaga agar kondisi mesin tetap stabil agar tidak memicu timbulnya kerusakan produk.

4. Metode kerja, sebaiknya melakukan pengerjaan proses sesuai dengan metode kerja yang telah ditentukan / terencanan dan sistematis.

5. Untuk lingkungan kerja, sebaiknya diperhatikan kenyamanan lingkungan kerja, dan dilakukan perbaikan terhadap tempat kerja agar operator dapat bekerja degan baik yaitu dengan lingkungan kerja yang bersih.

Copyright ( 2018, Kaizen : Management Systems \& Industrial Engineering Journal ISSN 15222-96806 (print), ISSN 155222-95973 (online) 


\section{KAIZEN : MANAGEMENT SYSTEMS \& INDUSTRIAL ENGINEERING JOURNAL VOL. 3 NO. 2 TEKNIK INDUSTRI UNIVERSITAS PGRI MADIUN}

Hasil usulan perbaikan maka selanjutnya dapat dibuat siklus PDCA-nya agar dapat dilakukan perbaikan yang berkelanjutan pada setiap kriteria cacat yang ada sebagai berikut :

1. Plan (Perencanaan)

Berdasarkan dari diagram sebab maka dapat dibuat rencana penanggulangan masalah cacat bubuk kopi dari 4 faktor permasalahan yaitu faktor manusia, lingkungan, metode dan bahan baku seperti pada Tabel 2.

Tabel 2. Rencana Penanggulangan Masalah Cacat Bubuk Kopi

\begin{tabular}{|c|c|c|c|c|c|}
\hline $\begin{array}{c}\text { What (Apa } \\
\text { factor } \\
\text { penyebab } \\
\text { masalahnya) } \\
\end{array}$ & $\begin{array}{c}\text { Why } \\
\text { (Alasan } \\
\text { perbaikan) }\end{array}$ & $\begin{array}{c}\text { Where } \\
\text { (Lokasi } \\
\text { perbaikan) }\end{array}$ & $\begin{array}{c}\text { How } \\
\text { (Bagaimana } \\
\text { tindakan } \\
\text { perbaikannya) }\end{array}$ & $\begin{array}{c}\text { When } \\
\text { (Kapan } \\
\text { Waktu } \\
\text { Pelaksanaan) } \\
\end{array}$ & $\begin{array}{c}\text { Who } \\
\text { (Pelaksana) }\end{array}$ \\
\hline \multirow[b]{2}{*}{ Lingkungan } & $\begin{array}{l}\text { Cuaca } \\
\text { kurang } \\
\text { menentu }\end{array}$ & $\begin{array}{l}\text { Tempat } \\
\text { kerja }\end{array}$ & $\begin{array}{l}\text { Menggunakan mesin } \\
\text { drayer/mesin } \\
\text { pengering }\end{array}$ & $\begin{array}{l}\text { Saat musim } \\
\text { penghujan }\end{array}$ & Petani Kopi \\
\hline & $\begin{array}{l}\text { Suhu udara } \\
\text { lembab }\end{array}$ & $\begin{array}{l}\text { Gudang } \\
\text { penyimpan } \\
\text { barang }\end{array}$ & $\begin{array}{l}\text { Memberikan cat pada } \\
\text { ruangan dengan cat } \\
\text { yang dapat meresap } \\
\text { air. }\end{array}$ & $\begin{array}{l}\text { Saat cuaca } \\
\text { dingin }\end{array}$ & $\begin{array}{l}\text { Kepala } \\
\text { produksi dan } \\
\text { karyawan }\end{array}$ \\
\hline \multirow[t]{2}{*}{ Manusia } & $\begin{array}{l}\text { Terburu- } \\
\text { buru }\end{array}$ & $\begin{array}{l}\text { Ruangan } \\
\text { kerja }\end{array}$ & $\begin{array}{l}\text { Memberikan nasihat } \\
\text { pada operator yang } \\
\text { kurang terburu-buru } \\
\text { agar lebih berhati-hati } \\
\text { dalam bekerja }\end{array}$ & $\begin{array}{l}\text { Selesai jam } \\
\text { kerja }\end{array}$ & $\begin{array}{l}\text { Kepala } \\
\text { Produksi }\end{array}$ \\
\hline & $\begin{array}{l}\text { Kurang } \\
\text { disiplin }\end{array}$ & $\begin{array}{l}\text { Ruang } \\
\text { Meeting }\end{array}$ & $\begin{array}{l}\text { Melakukan briefing } \\
\text { dan juga pelatihan } \\
\text { pada operator }\end{array}$ & $\begin{array}{l}\text { Sebelum } \\
\text { masuk Jam } \\
\text { kerja }\end{array}$ & $\begin{array}{l}\text { Kepala } \\
\text { Produksi }\end{array}$ \\
\hline \multirow[b]{2}{*}{ Metode } & $\begin{array}{l}\text { Kurang } \\
\text { Koordinasi }\end{array}$ & $\begin{array}{l}\text { Lantai } \\
\text { peroduksi }\end{array}$ & $\begin{array}{l}\text { Metode kerja harus } \\
\text { betul-betul difahami } \\
\text { oleh operator atau } \\
\text { disusun secara } \\
\text { sistematis }\end{array}$ & $\begin{array}{l}\text { Setiap } \\
\text { Bekerja }\end{array}$ & $\begin{array}{l}\text { Kepala } \\
\text { produksi dan } \\
\text { operator }\end{array}$ \\
\hline & $\begin{array}{l}\text { Kurang } \\
\text { terencana }\end{array}$ & $\begin{array}{l}\text { Lantai } \\
\text { produksi }\end{array}$ & $\begin{array}{l}\text { Metode } \\
\text { harusnya tidak hanya } \\
\text { berupa lisan, tetapi } \\
\text { harus diberikan } \\
\text { tulisan disetiap tempat } \\
\text { kerja. }\end{array}$ & Setiap bekerja & $\begin{array}{l}\text { Kepala } \\
\text { produksi }\end{array}$ \\
\hline Bahan baku & $\begin{array}{l}\text { Kadar air } \\
\text { Tinggi }\end{array}$ & $\begin{array}{l}\text { Lantai } \\
\text { produksi }\end{array}$ & $\begin{array}{l}\text { Melakukan } \\
\text { Pengeringan secara } \\
\text { maksimal }\end{array}$ & Setiap bekerja & Petani kopi \\
\hline
\end{tabular}

2. Do (Pelaksanaan)

Setelah dibuat perencanaan, maka langkah berikutnya adalah tahap pelaksanaan (do) dari rencana yang telah dibuat dan ditetapkan diatas. Adapun tahap pelaksanaan penanggulangan masalah cacat tersebut meliputi pada produk cacat seperti pada Tabel 3 .

Tabel 3. Pelaksanaan Penanggulangan Masalah Cacat Bubuk Kopi

\begin{tabular}{|c|c|c|c|c|}
\hline Masalah & Tindakan & Kapan/Waktu & Dimana & Pelaksana \\
\hline $\begin{array}{l}\text { Lingkungan kerja } \\
\text { cuaca yang kurang } \\
\text { menentu dan suhu } \\
\text { udara lembab. }\end{array}$ & $\begin{array}{l}\text { Memanfaatkan situasi } \\
\text { cuaca panas yang ada. }\end{array}$ & $\begin{array}{l}\text { Setiap hari, } \\
\text { khususnya pada } \\
\text { musim kemarau. }\end{array}$ & $\begin{array}{l}\text { Tempat pengeringan } \\
\text { biji kopi baik diluar } \\
\text { maupun } \\
\text { ruangan. }\end{array}$ & Operator. \\
\hline $\begin{array}{lr}\text { Manusia } & \text { yang } \\
\text { terlalu } & \text { terburu- } \\
\text { buru, dan } & \text { kurang } \\
\text { disiplin. } & \end{array}$ & $\begin{array}{l}\text { Memberikan pengarahan } \\
\text { serta nasehat agar dapat } \\
\text { selalu tenang dalam } \\
\text { bekerja. }\end{array}$ & $\begin{array}{l}\text { Setiap ada hal-hal } \\
\text { yang tidak sesuai. }\end{array}$ & Ruang meeting. & $\begin{array}{l}\text { Kepala } \\
\text { produksi. }\end{array}$ \\
\hline
\end{tabular}

Copyright (C) 2018, Kaizen : Management Systems \& Industrial Engineering Journal ISSN 15222-96806 (print), ISSN $155222-95973$ (online) 
KAIZEN : MANAGEMENT SYSTEMS \& INDUSTRIAL ENGINEERING JOURNAL VOL. 3 NO. 2 TEKNIK INDUSTRI UNIVERSITAS PGRI MADIUN

Tabel 4. Pelaksanaan Penanggulangan Masalah Cacat Bubuk Kopi (Lanjutan)

\begin{tabular}{|l|l|l|l|l|}
\hline \multicolumn{1}{|c|}{ Masalah } & \multicolumn{1}{|c|}{ Tindakan } & Kapan/Waktu & \multicolumn{1}{c|}{ Dimana } & Pelaksana \\
\hline $\begin{array}{l}\text { Metode kerja } \\
\text { kurang terencana. }\end{array}$ & $\begin{array}{l}\text { Metode } \\
\text { direncanakan lebih dulu } \\
\text { dan lebih sistematis. }\end{array}$ & Setiap bekerja & Di semua area kerja. & $\begin{array}{l}\text { Kepala } \\
\text { produksi, } \\
\text { karyawan. }\end{array}$ \\
\hline $\begin{array}{l}\text { Bahan baku kurang } \\
\text { baik kadar air } \\
\text { masih tinggi }\end{array}$ & $\begin{array}{l}\text { Setiap selesai pencucian, } \\
\text { bahan baku supaya } \\
\text { ditiriskan } \\
\text { maksimal. }\end{array}$ & $\begin{array}{l}\text { Di tempat lantai } \\
\text { produksi area kerja } \\
\text { pada pecara } \\
\text { pengeringan proses }\end{array}$ & Operator. \\
\hline
\end{tabular}

3. Check (Pemeriksaan)

Perbaikan yang dilakukan diperiksa apakah hasilnya sudah baik, apabila hasilnya belum baik, ulangi kembali langkah-langkah mulai dari permulaan lagi sampai tercapai hasil yang memuaskan. Tiap kali dibuat diagram pareto, histogram, dan diagram sebab akibat untuk mengetahui perbaikan yang telah dicapai.

4. Action (Tindakan)

Untuk mencegah kembali terulangnya masalah yang sama, maka perlu dibuat suatu peraturan dan tata cara kerja standar mutu yaitu :

a. Kondisi lingkungan kerja dibuat lebih mendukung kegiatan kerja

b. Operator diharuskan untuk makan sebelum memulai pekerjaannya agar tidak kehabisan tenaga saat beraktivitas.

c. Pemeriksaan bahan baku dilakukan pada saat bahan baku diterima.

d. Metode kerja direncanakan lebih dahulu dan dibuat lebih sistematis.

e. Menggunakan peralatan mesin yang layak pakai.

Faktor yang menyebabkan bubuk kopi menggumpal di setiap tahap proses produksi adalah sebagai berikut :

1. Proses pengeringan

Pada proses pengeringan penyebab kecacatan pada faktor manusia adalah pekerja yang terlalu teledor yang kurang memperhatikan SOP perusahaan sehingga proses pengeringan kurang maksimal. Sedangkan pada faktor lingkungan, cuaca yang kurang menentu dan ruangan penyimpanan hasil pengeringan yang terlalu sempit sehingga mengakibatkan suhu udara yang pengap.

2. $\quad$ Proses pemilihan biji kopi

Pada proses pemilihan biji kopi penyebab kecacatan adalah manusia yang kelelahan karena terlalu lama duduk sehingga kurang fokus dalam pemilihan dan lingkungan yang terlalu kotor karena biji kopi yang berserakan di lantai membuat orang risih.

3. Proses pengsangraian

Pada proses pengsangraian penyebab kecacatan adalah manusia yang kurang terampil sehingga mengakibatkan proses sangrai kurang maksimal serta kelelahan karena udara diruangan terlalu panas karena kurangnya fentilasi udara yang ada. Untuk faktor lingkungan dengan adanya barang yang tidak begitu penting membuat ruangan menjadi terlihat sempit. Metode yang kurang terkoordinir yang berakibat tidak sesuai SOP saat bekerja.

4. Proses pendinginan

Pada proses pendinginan penyebab kecacatan yang terjadi karena kurang maksimalnya pendinginan yang disebabkan terburu-burunya operator. Dan kurang telitinya dalam menjalankan SOP perusahaan.

5. Proses penggilingan

Pada proses penggilingan faktor penyebab kecacatan adalah faktor mesin yang kurang perawatan dan umur mesin yang terlalu tua sehingga sering terjadi troble. Untuk bahan baku yang kurang baik juga dapat mempengaruhi timbulnya hasil gilingan menjadi kasar.

6. Proses pengemasan

Pada proses pengemasan penyebab kecacatan adalah manusia yang kurang teliti dan lingkungan kerja yang kurang nyaman dengan adanya barang-barang yang berserakan seperti plastik dan timba yang berada tidak pada tempatnya.

7. Gudang penyimpanan

Pada penyimpanan, gudang yang terlalu banyak barang dan ruangan yang sempit mengakibatkan suhu udara pengap yang dapat mengakibatkan bubuk kopi hasil kemasan mudah untuk menggumpal.

Copyright (C) 2018, Kaizen : Management Systems \& Industrial Engineering Journal ISSN 15222-96806 (print), ISSN 155222-95973 (online) 


\section{KAIZEN : MANAGEMENT SYSTEMS \& INDUSTRIAL ENGINEERING JOURNAL VOL. 3 NO. 2 TEKNIK INDUSTRI UNIVERSITAS PGRI MADIUN}

Berdasarkan tahapan proses produksi di CV. Graha Rejeki indonesia, maka usulan gerakan 5S yang dapat dibuat adalah sebagai berikut [13]:

1. Seiri (Pemilahan)

Pelaksanaan Pemilahan difokuskan pada proses pengemasan, yaitu :

a. Memisahkan peralatan dan bahan baku yang siap dipakai produksi dan yang belum seperti plastik kemasan dan timba berisi bubuk kopi.

b. Mengelompokkan barang atau bahan menurut kepentinganya.

c. menyimpan atau membuang barang yang tidak diperlukan pada proses produksi.

2. Seiton (Penataan)

Pelaksanaan penataan/ kerapian ini difokuskan pada gudang penyimpanan yaitu :

a. Mengatur tata letak produk kopi sesuai dengan jenis aneka rasanya agar lebih mudah dalam mencarinya.

b. Menyiapkan tempat berupa rak beserta fasilitasnya.

c. Meletakkan barang pada tempat yang telah ditentukan.

d. Memberikan label pada barang yang telah disusun.

e. Melakukan pemeriksaan secara berkala terhadap kondisi kerapian.

Langkah-langkah yang harus ditempuh menuju kerapian adalah peta peletakkan barang, tanda pengenal barang, tanda batas, persiapan tempat danpengelompokkan barang.

3. Seiso (Kebersihan)

Pelaksanaan kebersihan pada semua area proses demi kenyamanan kerja, yaitu dengan :

a. Membersihkan semua kotoran atau sampah pada peralatan, mesin dan tempat kerja pada tempat yang telah disediakan.

b. Menemukan sumber kotoran dan berusaha mencegah timbulnya kotoran tersebut.

c. Membiasakan diri menyediakan waktu untuk membersihkan peralatan dan tempat kerja.

Faktor Kebersihan :

a. Menetapkan tanggung jawab individu terhadap proses kebersihan.

b. Menyediakan fasilitas kebersihan, misalnya : tempat sampah, sapu, dan lain-lain.

c. Melaksanakan kampanye kebersihan.

d. Melakukan sistem pengawasan dan pemeriksaan kebersihan.

Keuntungan yang diperoleh dari pelaksanaan kebersihan :

a. Lingkungan kerja menjadi aman dan nyaman.

b. Kesehatan bisa terjaga.

c. Meningkatkan kualitas dari produktivitas.

d. Meningkatkan efisiensi waktu dan menekan biaya akibat kerusakan peralatan.

4. $\quad$ Seiketsu (Rawat)

Hal-hal dalam pelaksanaan pemantapan yang perlu diperbaiki adalah pada semua area proses, yaitu :

a. Menetapkan label tanggung jawab setiap pekerja.

b. Membuat gambaran SOP tiap area kerja

c. Memberikan tanda daerah berbahaya.

d. Membuat petunjuk arah.

e. Menempatkan warna peringatan.

f. Membuat petunjuk pemadam kebakaran.

g. Menyiapkan pengamanan.

Beberapa langkah dalam menuju pemantapan antara lain :

a. Pemeriksaan

b. Pola tindak lanjut

c. Mekanisme pantau

d. Penetapan kondisi tidak wajar

e. Penetuan mutu kendali

5. Shitsuke (Pembiasaan)

Langkah menuju pembiasaan yaitu kedisiplinan dalam memahami setiap peraturan kerja sebagai berikut :

a. Kesempatan belajar bagi karyawan dengan melakukan breafing.

b. Hubungan karyawan atau sosialisasi sesama pekerja agar dapat bekerja secara kompak

c. Teladan dari atasan.

d. Penetapan target bersama

Copyright (C) 2018, Kaizen : Management Systems \& Industrial Engineering Journal ISSN 15222-96806 (print), ISSN $155222-95973$ (online) 


\section{KAIZEN : MANAGEMENT SYSTEMS \& INDUSTRIAL ENGINEERING JOURNAL VOL. 3 NO. 2 TEKNIK INDUSTRI UNIVERSITAS PGRI MADIUN}

\section{Simpulan}

Dari hasil pengumpulan dan pengolahan data di atas dengan metode Kaizen maka peneliti dapat memberikan kesimpulan yaitu berdasarkan hasil analisa menggunakan fishbone diagram, maka dapat disimpulkan bahwa faktorfaktor yang menyebabkan kerusakan atau cacat pada produk coffee chocolate creamer adalah disebabkan oleh adanya faktor manusia yang kurang teliti dan kurang terampil saat bekerja, mesin yang kurang perawatan, metode yang kurang koordinasi, bahan baku kurang baik dan kurang atandart, dan lingkungan yang kurang nyaman dan juga cuaca yang kurang menentu. Peningkatan kualitas mutu pada produk kopi cokelat yang diusulkan dengan menggunakan siklus $P D C A$ dan $5 S$ yang memecahkan masalah dengan menentukan prioritas masalah berdasarkan diagram sebab akibat. Pada tahan PDCA dan 5S yaitu dengan melakukan pelatihan untuk meningkatkan kemampuan dan skil operator, peralatan mesin selalu dirawat agar kerusakan dapat diminimalkan, metode kerja lebih diperhatikan dengan baik, pemilihan bahan baku dengan lebih detail serta menciptakan lingkungan kerja yang aman, nyaman dan selalu memelihara serta merawat tempat kerja.

\section{Daftar Pustaka}

[1] V. Gaspers, Total Quality Management. Bogor: Vinchristo Publication, 2011.

[2] D. C. Montgomery, Introduction to Statistical Quality Control. New York: John Wiley \& Sons, Inc., 2009.

[3] N. N. R. Putra and M. Al Musadieq, "Analisis Penerapan Budaya Kaizen Pada Perusahaan Joint Venture Asal Jepang di Indonesia," J. Adm. Bisnis, vol. 57, no. 1, pp. 188-197, 2018.

[4] J. Heizer and B. Render, Operations Management (Manajemen Operasi). Jakarta: Salemba Empat, 2006.

[5] A. Fatkhurrohman, "Penerapan kaizen dalam Meningkatkan Efisiensi dan Kualitas Produk Pada Bagian Banbury PT. Bridgestone Tire Indonesia," J. Adm. Kant., vol. 4, no. 1, pp. 14-31, 2016.

[6] Darsono, "Analisis Pengendalian Kualitas Produksi dalam Upaya Mengendalikan Tingkat Kerusakan Produk," J. Ekon. Manaj. Akutansi, no. 35, pp. 1-17, 2013.

[7] S. Prawirosentono, Manajemen Berbasis Mutu. Jakarta: Bumi Aksara, 2007.

[8] M. Fitri, "Gemba Kaizen dan Hubungannya dengan Penerapan Sistem Manajemen Kualitas ISO9001," $J$. Teknol. Elektro, vol. 7, no. 1, 2016.

[9] H. Tannady, Pengendalian Kualitas. Yogyakarta: Graha Ilmu, 2015.

[10] S. Wignjosoebroto, Pengantar Teknik dan Manajemen Industri. Surabaya: Guna Widya, 2003.

[11] A. Adyatama and N. U. Handayani, "Perbaikan Kualitas Menggunakan Prinsip Kaizen Dan 5 Why Analysis : Studi Kasus Pada Painting Shop Karawang Plant 1, PT Toyota Motor Manufacturing Indonesia," J@ti Undip J. Tek. Ind., vol. 13, no. 3, pp. 169-176, 2018.

[12] A. Handoko, "Implementasi Pengendalian Kualitas dengan Menggunakan Pendekatan PDCA dan Seven Tools pada PT. Rosandex Putra Perkasa Di Surabaya," Calyptra J. Ilm. Mhs. Univ. Surabaya, vol. 6, no. 2, pp. 1329-1347, 2017.

[13] A. S. Nugraha, A. Desrianty, and L. Irianti, "Usulan Perbaikan Berdasarkan Metode 5S (Seiri, Seiton, Seiso, Seiketsu, Shitsuke) untuk Area Kerja Lantai Produksi di PT. X," Reka Integr. J. Tek. Ind., vol. 4, no. 3, pp. 219-229, 2015. 